\title{
Fibrinogen is associated with EGFR mutation status and lymphatic metastasis in non-small cell lung cancer
}

\author{
JIAN GUAN $^{1 *}$, NAN XIAO $^{1 *}$, CHUN QIU $^{1}$, QIN LI $^{1}$, MIN CHEN $^{1}$, YAO ZHANG $^{1}$, YONG DAI $^{1}$, \\ $\mathrm{LU} \mathrm{LI}^{1}$, YUE ZHANG ${ }^{1}$, MI YANG ${ }^{1}$, LONG CHEN ${ }^{1}$ and LAI YU LIU ${ }^{2}$ \\ ${ }^{1}$ Department of Radiation Oncology; ${ }^{2}$ Chronic Airways Diseases Laboratory, Department of Respiratory \\ and Critical Care Medicine, Nanfang Hospital, Southern Medical University, Guangzhou, Guangdong 510515, P.R. China
}

Received March 15, 2016; Accepted January 12, 2017

DOI: $10.3892 / \mathrm{ol} .2018 .9652$

\begin{abstract}
In the previous decade, tyrosine kinase inhibitors (TKIs) have demonstrated significant effects in patients with non-small cell lung cancer (NSCLC) with epidermal growth factor receptor (EGFR) mutations. However, sufficient tumor tissue for genetic testing cannot always be obtained in clinical settings. The present study evaluated whether fibrinogen may assist in predicting the EFGR mutation status in patients with NSCLC. Between January 2010 to December 2013, 303 patients with NSCLC underwent EGFR mutation testing. Plasma fibrinogen was acquired prior to treatment, and the associations between fibrinogen, EGFR mutation status and clinical features were assessed. A multivariate analysis and a receiver operator characteristic curve analysis were performed to identify the potential value of fibrinogen in predicting EGFR mutation status. The proportion of patients with hyperfibrinogenemia was significantly higher in N2 and N3 stages compared with N0 and N1 stages, 45.2 and 56.5 vs. 29.2 and $36.0 \%$, respectively $(\mathrm{P}=0.001)$, and higher in the $\mathrm{M} 1$ stage compared with the M0 stage, 47.9 vs. $35.2 \%$, respectively $(\mathrm{P}=0.025)$ (Stages according to the American Joint Committee of Cancer, 7th edition). Plasma fibrinogen levels were significantly lower in patients with EGFR mutations compared with the wild-type EGFR gene, $2.95 \mathrm{~g} / \mathrm{l}$ (range, $0.84-8.61 \mathrm{~g} / \mathrm{l})$ vs. $3.57 \mathrm{~g} / \mathrm{l}$ (range, 1.38-7.44 g/l), respectively
\end{abstract}

Correspondence to: Dr Lai Yu Liu, Chronic Airways Diseases Laboratory, Department of Respiratory and Critical Care Medicine, Nanfang Hospital, Southern Medical University, 1838 North Guangzhou Main Road, Baiyun, Guangzhou, Guangdong 510515, P.R. China

E-mail: 1iuly5461@163.com

Dr Long Chen, Department of Radiation Oncology, Nanfang Hospital, Southern Medical University, 1838 North Guangzhou Main Road, Baiyun, Guangzhou, Guangdong 510515, P.R. China E-mail: chenlh5461@163.com

${ }^{*}$ Contributed equally

Key words: fibrinogen, non-small cell lung cancer, epidermal growth factor mutation status, lymphatic metastasis, prediction
$(\mathrm{P}<0.001)$. In the multivariate analysis, logistic regression was utilized and the fibrinogen odds ratio (OR), 2.5, confidence intervals $(\mathrm{CI})$ 1.53-4.51 $(\mathrm{P}<0.001)$ and smoking status $\mathrm{OR}$ 5.07, CI 3.01-8.53 $(\mathrm{P}<0.001)$, for which the area under the curve was 0.75 , were revealed to be independent predictive factors. Hyperfibrinogenemia is associated with metastasis of the distant organs, but also metastasis of the lymphatic tissue. In addition, a multivariate model based on fibrinogen and smoking history may be used as a predictive marker of EGFR mutation status in patients with NSCLC.

\section{Introduction}

Non-small cell lung cancer (NSCLC) is the most common type of cancer and the main cause of cancer-associated mortalities in China (1). In the previous decade, the tyrosine kinase inhibitors (TKI) gefitinib and erlotinib, which specifically target the TK domain of the epidermal growth factor receptor (EGFR), have demonstrated longer progression-free survival in patients with NSCLC with EGFR mutations than in patients with wild-type EGFR $(2,3)$. Thus, it is important to establish the EGFR mutation status for the optimization of treatment in patients with NSCLC. However, sufficient tumor tissues cannot always be obtained for genetic testing in clinical settings. Therefore, developing noninvasive techniques to predict the EGFR mutation status may be of clinical use.

The level of fibrinogen, a major acute phase protein synthesized by the liver epithelium, increases in the blood in response to blood clotting, infection, wound healing, inflammation and neoplasia (4). It is increasingly recognized that levels of plasma fibrinogen are associated with human malignancies, such as lung, gastric, esophageal, ovarian and renal cancer (5-8). Fibrinogen, and other coagulation factors serve an important function in tumor cell growth, invasion and metastasis by supporting the sustained adhesion of tumor cells and by promoting tumor neoangiogenesis. Additionally, fibrinogen itself is able to directly bind to inflammatory cells, inducing synthesis of proinflammatory cytokines, and the inflammatory microenvironment of tumors effectively influences proliferation and migration of tumor cells. Previous studies have reported that hyperfibrinogenemia is correlated with lymphatic metastasis in gastric cancer and gallbladder carcinoma, but not in NSCLC (9-11). Additionally, no studies 
have demonstrated that plasma fibrinogen concentration in patients with NSCLC may be a predictor for EGFR gene mutation status. The aim of the present study was to investigate the correlation between plasma fibrinogen levels and EGFR gene mutation status in patients with NSCLC. A predictive model was also established for EGFR mutation status.

\section{Patients and methods}

Patient selection. The medical records of patients treated between January 2010 and December 2013 were retrospectively investigated at Nanfang Hospital (Guangzhou, China). All patients were confirmed to exhibit NSCLC and had not yet received any treatment. All patients met the following entry criteria: The patient underwent EGFR gene testing subsequent to histologic or cytological diagnosis; plasma fibrinogen was acquired prior to initiating treatment; positron emission tomography (PET)/computed tomography (CT) were performed prior to all treatment; histopathology was reviewed at Nanfang Hospital, Guangzhou, China. Patient characteristics including age, sex and smoking history were recorded prior to therapy. Tumor characteristics such as histology, clinical differentiated degree and clinical stage were acquired from the clinical pathology reports, and the clinical stage was specified based on the seventh edition of the American Joint Committee on Cancer Staging Manual (AJCC) (12). T1 stage, tumor $\leq 3 \mathrm{~cm}$ in diameter, surrounded by lung or visceral pleura, without bronchoscopic evidence of invasion more proximal than the lobar bronchus. T2 stage, tumor $>3 \mathrm{~cm}$ but $\leq 7 \mathrm{~cm}$ in diameter, or having any of the following features: Main bronchus $>2 \mathrm{~cm}$ from carina, invades visceral pleura and partial atelectasis. T3 stage, tumor $>7 \mathrm{~cm}$ in diameter or directly invading any of the following: Chest wall, diaphragm, pericardium or mediastinal pleura, or the main bronchus $<2 \mathrm{~cm}$ from carina, total atelectasis or separate nodule(s) in same lobe. T4 stage, tumor of any size that invades one or more of the following: Mediastinum, heart, large vessels, carina, trachea, oesophagus, vertebra; separate tumor nodule(s) in a different ipsilateral lobe.

Fibrinogen measurement. Blood samples from patients with NSCLC were obtained within the week prior to all treatment. Fibrinogen was measured by the Clauss method (Sysmex CA-1500; Sysmex Corporation, Kobe, Japan). Plasma fibrinogen concentrations of 1.8-3.5 g/l were considered normal, and concentrations of $>3.5 \mathrm{~g} / \mathrm{l}$ were defined as hyperfibrinogenemic based on the protocol of the manufacturer.

EGFR mutation analysis. EGFR mutations in exons 18-21 were detected by direct sequencing in the pathology department of Nanfang Hospital (Guangzhou, China) between 2010 and 2012. Genomic DNA was extracted from tumor specimens using the TaKaRa DEXPATTM kit (TaKaRa Bio, Inc., Ostu, Japan). Genomic DNA sequences were acquired by polymerase chain reaction (PCR)-based direct sequencing. The primers used were: Exon 18 sense, CAAATGAGCTGGCAAGTG CCGTGTC and antisense, GAGTTTCCCAAACACTCAGTG AAAC; Exon 19 sense, GCAATATCAGCCTTAGGTGCG GCTC and antisense, CATAGAAAGTGAACATTTAGG ATGTG; Exon 20 sense, CCATGAGTACGTATTTTGAAA CTC and antisense, CATATCCCCATGGCAAACTCTTGC;
Exon 21 sense, CTAACGTTCGCCAGCCATAAGTCC and antisense, GCTGCGAGCTCACCCAGAATGTCTGG. The appropriate PCR products were then sequenced in forward and reverse directions using the Version 3 ABI PRISM BigDye Terminator Cycle Sequencing Ready Reaction kit and an ABI PRISM 3730XL Genetic Analyzer (Applied Biosystems; Thermo Fisher Scientific, Inc., Waltham, MA, USA). The chromatograms were analyzed by a professional reviewer. The Amplification Refractory Mutation System (ARMS) was used to detect exons 18-21 in all samples sourced from 2013. All ARMS primer pairs were utilized for PCR with the following criteria: Concentration of $1 \mu \mathrm{M}$, control reaction primers at concentration $0.1 \mu \mathrm{M}$ and TaqMan probes at concentration $0.5 \mu \mathrm{M}$. DNA sequences were amplified by PCR.

The PCR cycling conditions were as follows: An initial denaturation at $95^{\circ} \mathrm{C}$ for 5 min followed by six cycles of $95^{\circ} \mathrm{C}$ for $30 \mathrm{sec}$, an annealing phase at $60^{\circ} \mathrm{C}$ for $90 \mathrm{sec}$, decreasing by $0.5^{\circ} \mathrm{C}$ every cycle until reaching $57^{\circ} \mathrm{C}$, and an elongation step of $72^{\circ} \mathrm{C}$ for $90 \mathrm{sec}$. This was followed by an additional 45 cycles as described herein, with an annealing temperature of $57^{\circ} \mathrm{C}$, and finally an elongation step at $72^{\circ} \mathrm{C}$ for $10 \mathrm{~min}$. According to standard protocols, PCR products were sequenced in both sense and anti-sense directions using an ABI PRISM ${ }^{\circledR} 9700$ Genetic Analyzer (Applied Biosystems, Foster City, CA, USA). The quantification cycle $(\mathrm{Cq})$ values of the target gene and reference genes were obtained from the PCR data by a DxS EGFR mutation test kit (Manchester, UK), according to the manufacturer's protocols.

Statistical analysis. Plasma fibrinogen was analyzed as a categorical variable and a continuous variable subsequent to grouping by normal levels and hyperfibrinogenemia. Continuous covariates were analyzed using a Wilcoxon rank-sum test or a Student's t-test. Categorical covariates were analyzed with a Fisher's exact test or Pearson chi-squared test as appropriate. Logistic regression analysis was performed to test the variables which were associated with EGFR mutation status in univariate analysis. Subsequently, the area under the curve (AUC) of the receiver operator characteristic (ROC) curve was used for measuring the predictive value. $\mathrm{P}<0.05$, which derived from two-sided tests, and was considered to indicate a statistically significant difference. The values are given as mean \pm standard deviation if appropriate. All experiments were repeated three times. Analyses were performed with SPSS 21.0 (IBM SPSS, Armonk, NY, USA) for all statistical calculations.

\section{Results}

Plasma fibrinogen concentration and characteristics of patients. The association between plasma fibrinogen and the general characteristics of patients is summarized in Table I. A total of 178 patients $(58.7 \%)$ exhibited low plasma fibrinogen concentrations $(\leq 3.5 \mathrm{~g} / \mathrm{l})$, whereas $125(41.3 \%)$ exhibited high serum fibrinogen concentrations $(>3.5 \mathrm{~g} / \mathrm{l})$. Low plasma fibrinogen concentration was significantly associated with several variables, including female sex, never smokers, adenocarcinoma histopathology, well-differentiated tumor grading and AJCC stage I tumors (Table I). When the primary tumor sizes were classified into five groups, $\leq 2,2.01-3,3.01-5,5.01-7$, 
Table I. Associations between serum fibrinogen level with clinical factors in patients with NSCLC.

\begin{tabular}{|c|c|c|c|}
\hline Characteristic & $\begin{array}{l}\text { Low fibrinogen }(\mathrm{n}=178) \\
\qquad \begin{array}{c}(\leq 3.5 \mathrm{~g} / \mathrm{l}) \\
\mathrm{n}(\%)\end{array}\end{array}$ & $\begin{array}{l}\text { High fibrinogen }(\mathrm{n}=125) \\
\qquad \begin{array}{c}(>3.5 \mathrm{~g} / \mathrm{l}) \\
\mathrm{n}(\%)\end{array}\end{array}$ & P-value \\
\hline Age, mean (SD) & $59(11.73)$ & $61(11.23)$ & 0.174 \\
\hline Sex & & & 0.045 \\
\hline Male & $113(54.9)$ & $93(45.1)$ & \\
\hline Female & $65(67.0)$ & $32(33.0)$ & \\
\hline Smoking history & & & $<0.001$ \\
\hline Ever & $74(47.7)$ & $81(52.3)$ & \\
\hline Never & $104(70.3)$ & $44(29.7)$ & \\
\hline Histopathology & & & $<0.001$ \\
\hline Adenocarcinoma & $152(65.5)$ & $80(34.5)$ & \\
\hline Squamous cell carcinoma & $16(32.7)$ & $33(67.3)$ & \\
\hline Others & $10(45.5)$ & $12(54.5)$ & \\
\hline Tumor grade $^{a}$ & & & 0.001 \\
\hline Well-differentiated & $39(83.0)$ & $8(17.0)$ & \\
\hline Moderately differentiated & $43(58.1)$ & $31(41.9)$ & \\
\hline Poorly differentiated & $70(52.6)$ & $63(47.4)$ & \\
\hline AJCC stage & & & 0.002 \\
\hline I & $54(78.3)$ & $15(21.7)$ & \\
\hline II & $12(46.2)$ & $14(53.8)$ & \\
\hline III & $37(57.8)$ & $27(42.2)$ & \\
\hline IV & $75(52.1)$ & 69 (47.9) & \\
\hline
\end{tabular}

ancluding 254 patients. AJCC, American Joint Committee on Cancer.

and $>7 \mathrm{~cm}$, there was a positive correlation between plasma fibrinogen concentration and tumor size, $3.03 \pm 1.18,3.16 \pm 1.09$, $3.71 \pm 1.12,3.96 \pm 1.24$ and $4.48 \pm 1.19$, respectively $(\mathrm{P}<0.001)$, as demonstrated in Fig. 1A. The level of plasma fibrinogen was significantly higher in $\mathrm{T} 2, \mathrm{~T} 3$ or $\mathrm{T} 4$ stage tumors compared with T1 stage tumors, 3.55 $\pm 1.09,3.70 \pm 1.29$ and $3.90 \pm 1.29$ vs. $3.01 \pm 1.19$, respectively $(\mathrm{P}<0.001)$, as illustrated in Fig. 1B, and was significantly higher in $\mathrm{M}_{1}$ stage tumors compared with $\mathrm{M}_{0}$ stage tumors, $3.81 \pm 1.33$ vs. $3.28 \pm 1.07$, respectively $(\mathrm{P}=0.025)$, as demonstrated in Fig. $1 \mathrm{C}$. The proportion of patients with high fibrinogen concentration was significantly higher in N2 and N3 stage tumors compared with N0 and N1 stage tumors, 45.2 and 56.5 vs. 29.2 and $36.0 \%$, respectively ( $\mathrm{P}=0.001)$, as illustrated in Fig. 1D.

Patient characteristics and EGFR mutation status. The baseline characteristics of the patients are listed in Table II. In total, 303 histologically verified patients with NSCLC, with a mean age of $60 \pm 11.6$ years, 97 females and 206 males, were included. A total of 121 patients, 39.9\%, were positive for an EGFR mutation. The EGFR mutations were more frequent in female patients compared with males, 62.9 vs. $29.1 \%$, respectively $(\mathrm{P}<0.001)$. A total of 148 patients, 48.8\%, were never smokers, followed by 127 patients, $41.9 \%$, who were smokers and 28 patients, 9.2\%, who used to smoke. For statistical analyses, the smokers and who used to smoke were combined into an smoking group $(n=155 ; 51.2 \%)$. The EGFR mutations were more frequent in non-smokers compared with smokers, 60.1 vs. $20.6 \%$, respectively $(\mathrm{P}<0.001)$, as demonstrated in Fig. 2A. There were 232 patients, $76.6 \%$, with adenocarcinoma. EGFR mutations were more frequent in patients with adenocarcinoma $(\mathrm{P}<0.001)$. A total of 133 patients, $43.9 \%$, were diagnosed as poorly differentiated, whereas 47 patients, $15.5 \%$, and 74 patients, $24.4 \%$, were diagnosed as well-differentiated and moderately differentiated, respectively. In 49 patients, $16.2 \%$, information about the tumor grade was missing. Almost half of the patients were diagnosed at stage IV $(\mathrm{n}=144 ; 47.5 \%)$, whereas 69 patients $(22.8 \%) 26$ patients $(8.6 \%)$ and 64 patients $(21.1 \%)$ were detected at stages I, II and III, respectively.

Association between plasma fibrinogen and EGFR mutation status. Plasma fibrinogen levels were significantly lower in patients with EGFR mutations compared with the wild-type EGFR gene, $2.95 \mathrm{~g} / 1$ (range, 0.84-8.61 g/l) vs. $3.57 \mathrm{~g} / 1$ (range, 1.38-7.44 g/l), respectively $(\mathrm{P}<0.001)$, as demonstrated in Fig. 2B. Patients were allocated into two groups with a cut-off level of normal fibrinogen level of $3.5 \mathrm{~g} / 1$. A total of 125 patients were allocated to the elevated fibrinogen group $(>3.5 \mathrm{~g} / \mathrm{l})$ and 178 patients were allocated to the non-elevated fibrinogen group $(\leq 3.5 \mathrm{~g} / \mathrm{l})$. The incidence of EGFR mutations in the non-elevated fibrinogen group was higher compared with the elevated fibrinogen group, 51.1 vs. $24.0 \%$, respectively $(\mathrm{P}<0.001)$. In the univariate logistic regression analysis, 
$\mathbf{A}$

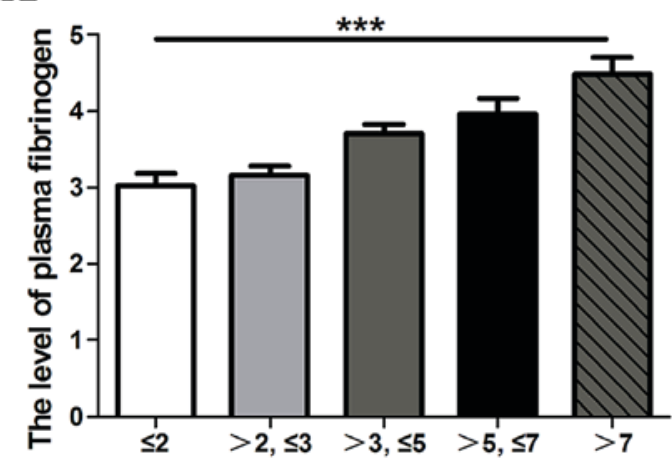

C

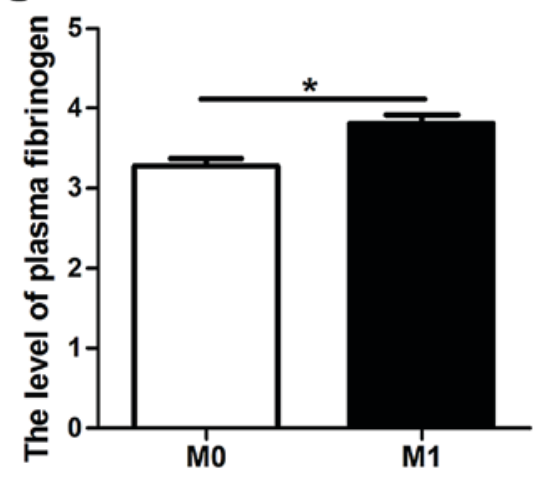

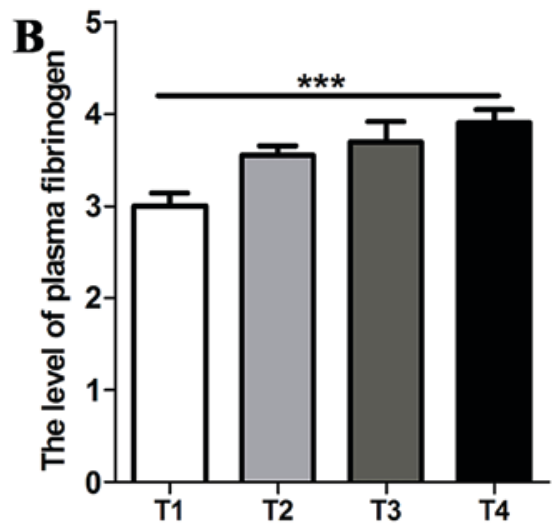

D

$\square$ Low fibrinogen

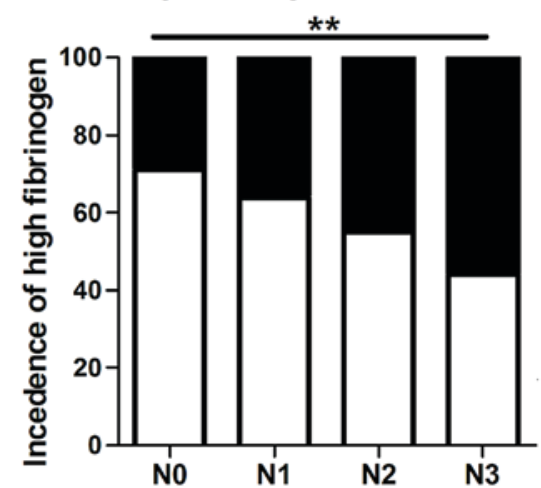

Figure 1. (A) Level of fibrinogen according to primary tumor size (B) Level of fibrinogen according to T stage (C) Level of fibrinogen according to M stage (D) Incidence of high fibrinogen (hyperfibrinogenemia) according to primary tumor size. Data are represented as the mean \pm standard error of the mean. ${ }^{*} \mathrm{P}<0.05,{ }^{* *} \mathrm{P}<0.001,{ }^{* * *} \mathrm{P}<0.001$.

the ORs of EGFR mutations (OR, 0.30; 95\% CI, 0.18-0.50; $\mathrm{P}<0.001)$ were significantly decreased in patients in the elevated fibrinogen group. ROC curve analysis was performed to demonstrate that the fibrinogen cut-off point was 3.5 , as illustrated in Table II, and the AUC of the ROC curve was 0.64 (95\% CI, 0.57-0.70; Fig. 3). For additional analyses, fibrinogen levels were dichotomized into groups according to the 75th percentile of the total study population. An elevated level of fibrinogen, with a cut-off of $4.2 \mathrm{~g} / 1$, was present in 228 patients, $25 \%$. The ORs of EGFR mutations (OR, 0.41; 95\% CI, 0.23-0.75; $\mathrm{P}=0.004)$ were significantly decreased in patients with elevated fibrinogen group. ROC curve analysis was performed to show that the fibrinogen cutoff point was 3.5, as illustrated in Table III, and AUC of the ROC curve was 0.57 (95\% CI, 0.51-0.64), as demonstrated in Fig. 3.

An elevated level of fibrinogen was associated with patients who smoked $(\mathrm{P}<0.001)$. The majority of smoking patients $(n=74,91.4 \%)$ in the elevated fibrinogen group $(>3.5 \mathrm{~g} / \mathrm{ml})$ was associated with wild-type EGFR $(\mathrm{P}<0.001)$. However, in nonsmoking patients, no statically significant association was observed between fibrinogen and EGFR mutation status. The incidence of EGFR mutations of non-elevated fibrinogen group $(\leq 3.5 \mathrm{~g} / \mathrm{ml})$ was high compared with the elevated fibrinogen group in adenocarcinoma (55.3 vs. $30.0 \%$; $\mathrm{P}<0.001)$, whereas no statistically significant association was observed between fibrinogen and EGFR mutation status in squamous cell carcinoma and others, determined via histopathology. The incidence of EGFR mutations of non-elevated fibrinogen group $(\leq 3.5 \mathrm{~g} / \mathrm{ml})$ was higher compared with the elevated fibrinogen group in poorly differentiated (47.1 vs. 19.0\%; $\mathrm{P}=0.001)$, whereas no statistically significant association was observed between fibrinogen and EGFR mutation status in the other tumor grade. At stage I, III and IV, the incidence of EGFR mutations of non-elevated fibrinogen group was significantly higher compared with the elevated fibrinogen group in adenocarcinoma $(\mathrm{P}<0.05)$. There was a trend of lower incidence of EGFR mutations in the elevated fibrinogen group compared with the non-elevated fibrinogen group, though it was not statistically significant at stage II.

Multivariate analysis of various predictive factors of EGFR mutation status. In the univariate analysis, EGFR mutation status was significantly associated with sex, smoking status, tumor histology, tumor differentiated degree, tumor stage and fibrinogen, as summarized in Table II. In order to clarify which was the independent predictive factor of EGFR mutations, a multivariate analysis was performed. Logistic regression was utilized and the model was adjusted for sex, smoking history, histopathology, tumor grade, stage and fibrinogen. Fibrinogen (OR 2.5, CI 1.53-4.51, $\mathrm{P}<0.001$ ) and smoking status (OR 5.07, CI 3.01-8.53, $\mathrm{P}<0.001$ ) were revealed to be independent predictive factors subsequent to multivariate analyses, whereas sex, tumor histology, tumor differentiated degree and tumor stage exhibited no independent predictive impact on EGFR mutation status in the study population. 
Table II. Associations between clinical features and EGFR mutation.

\begin{tabular}{|c|c|c|c|}
\hline Characteristic & $\begin{array}{l}\text { Wild-type EGFR }(\mathrm{n}=182) \\
\mathrm{n}(\%)\end{array}$ & $\begin{array}{c}\text { Mutant EGFR }(\mathrm{n}=121) \\
\mathrm{n}(\%)\end{array}$ & P-value \\
\hline Age, median (range) & $60(24-87)$ & $60(30-82)$ & 0.89 \\
\hline Sex & & & $<0.001$ \\
\hline Male & $146(70.9)$ & $60(29.1)$ & \\
\hline Female & $36(37.1)$ & $61(62.9)$ & \\
\hline Smoking history & & & $<0.001$ \\
\hline Ever & $123(79.4)$ & $32(20.6)$ & \\
\hline Never & $59(39.9)$ & $89(60.1)$ & \\
\hline Histopathology & & & $<0.001$ \\
\hline Adenocarcinoma & $124(53.4)$ & $108(46.6)$ & \\
\hline Squamous cell carcinoma & $41(83.7)$ & $8(16.3)$ & \\
\hline Others & $17(77.3)$ & $5(22.7)$ & \\
\hline Tumor grade $^{\mathrm{a}}$ & & & 0.02 \\
\hline Well-differentiated & $19(40.4)$ & $28(59.6)$ & \\
\hline Moderately differentiated & $44(59.5)$ & $30(40.5)$ & \\
\hline Poorly differentiated & $88(66.2)$ & $45(33.8)$ & \\
\hline AJCC stage & & & 0.01 \\
\hline I & $39(56.5)$ & $30(43.5)$ & \\
\hline II & $19(73.1)$ & 7 (26.9) & \\
\hline III & $48(75.0)$ & $16(25.0)$ & \\
\hline IV & $76(52.8)$ & $68(47.2)$ & \\
\hline
\end{tabular}

${ }^{\text {ancluding }} 254$ patients. AJCC, American Joint Committee on Cancer; EGFR, epithelial growth factor receptor.
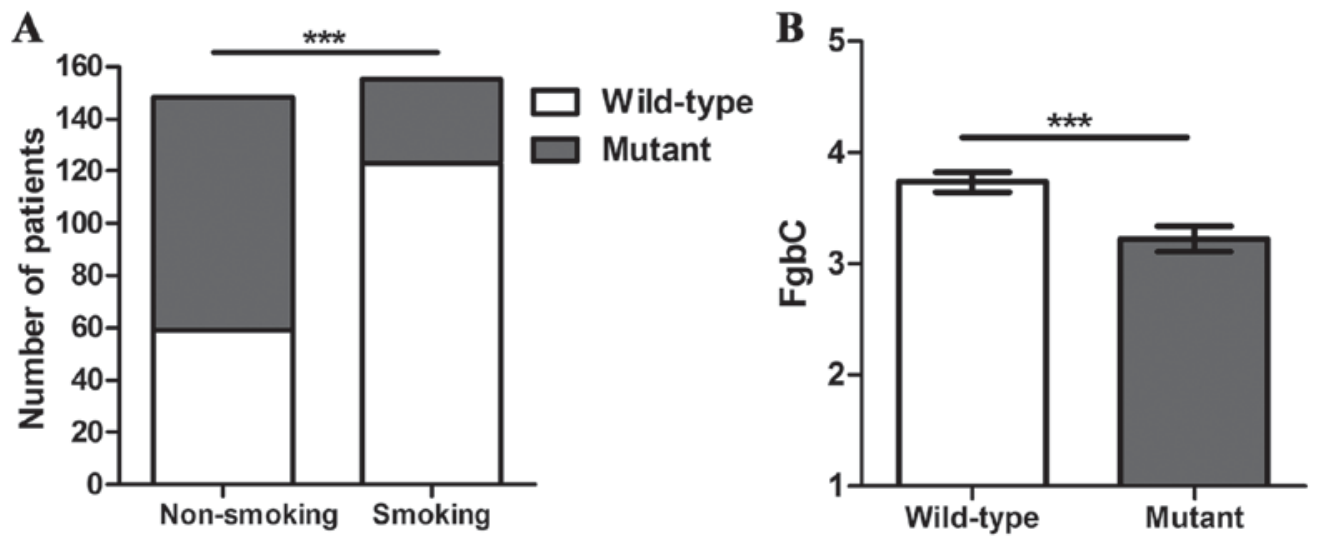

Figure 2. (A) The number of patients with different EGFR mutation status in non-smoking group and smoking group. (B) Mean value of plasma fibrinogen in different EGFR mutation status. Data are represented as the mean \pm standard error of the mean. ${ }^{* * *} \mathrm{P}<0.001$. FgbC, fibrinogen; EGFR, epidermal growth factor receptor.

Finally, the sensitivity and specificity of plasma fibrinogen levels and smoking status in predicting EGFR mutation status were investigated and ROC analysis was performed. When the predictive model included either plasma fibrinogen levels or smoking status, the AUC for prognosticating EGFR mutation status was 0.65 (95\% CI: 0.59-0.72) and 0.71 (95\% CI: $0.65-0.77)$, respectively. When the predictive model included plasma fibrinogen levels and smoking status together, the AUC for prognosticating EGFR mutation status was 0.75 (95\% CI: 0.70-0.81), indicating that the model with two factors possessed higher accuracy for predicting EGFR mutation status compared with the model with only one factor in NSCLC, as demonstrated in Fig. 3.

\section{Discussion}

The association between the progression of malignancies and coagulation has been investigated (13). The activation of coagulation and fibrinolysis in patients with NSCLC is closely associated with tumor invasion, metastasis and poorer prognosis (14). Hypercoagulability is an indication of more aggressive disease states. Amongst patients with NSCLC, 
high plasma concentrations of fibrinogen, platelet counts and D-dimers are associated with poor prognosis (15). Additionally, anticoagulant drugs such as heparin with low molecular weights exhibited a significant antitumor effect without increasing the incidence of venous thromboembolism (16).

In the present study, plasma fibrinogen concentration was significantly associated with clinical characteristics. Hyperfibrinogenemia was associated with male sex and squamous cell carcinoma histopathologies. In addition, plasma fibrinogen concentration was higher in smokers compared with in nonsmokers, whilst a previous study reported that high fibrinogen levels were associated with smoking-associated types of cancer (17). High fibrinogen concentration was associated with poorly differentiated and advanced stage tumors. Notably, an association was identified between high fibrinogen levels and advanced $\mathrm{T}$ stage, which was also consistent with a previous study (11).

Elevated coagulation may be a key factor of the possibility of metastasis, such as circulating tumor cells. Fibrinogen promotes platelets to adhere to tumor cells, and the aggregates of platelet-fibrin-tumor cell complexes may lead to potential metastasis by preventing the natural killercells from eliminating tumor cells (18). In addition, animal models have confirmed that fi In addition, anim may strongly diminish tumor size, but did not prevent lung metastasis (19). This phenomenon is due to the fact that fibrinogen maintains adhesion to the circulating tumor cells (20). These data are important as they suggest an association between fibrinogen and $\mathrm{M}$ stage. This association was also demonstrated in the present study. Notably, it was revealed that hyperfibrinogenemia was associated with lymphatic metastasis, similar with the results of previous studies in gastric and gallbladder cancer $(9,10)$. Additionally, Palumbo et al (21) demonstrated that the incidence of metastases in regional lymph nodes was markedly reduced in fibrinogen-deficient mice with subcutaneously inoculated Lewis lung cell carcinoma. However, Jones et al (11) revealed that hyperfibrinogenemia was not associated with lymphatic metastasis in NSCLC. The reasons for these conflicting results may be associated with the fact that the previous study was based on a relatively small sample and the majority of the patients $(92.5 \%)$ were of $\mathrm{N}_{0}$ stage: Additionally, all of the patients underwent CT scanning instead of PET/CT scanning. Therefore, hyperfibrinogenemia may be associated with distant organ metastasis and lymphatic metastasis.

In the present study, EGFR mutation status was significantly associated with sex, smoking history, histopathology, tumor grade and clinical stage, which was also verified by previous studies $(22,23)$. EGFR mutations were associated with the nonsmoking study population. These data were consistent with those of previous studies. EGFR gene mutations located between the CAAGGAA repeats were preponderantly in-frame deletions in NSCLC of non-smoking patients with NSCLC (24). In the present study, the proportion of EGFR gene mutations were low in smoking patients, which was consistent with previous studies.

To our knowledge, this is the first study investigating the association between plasma fibrinogen concentration and EGFR gene mutation status. Hyperfibrinogenemia was revealed to be associated with the wild-type EGFR. Additionally, logistic regression analysis revealed that plasma fibrinogen and
Table III. Multivariate analysis for various predictive factors of epithelial growth factor receptor mutations.

\begin{tabular}{lccc}
\hline Variable & Odds ratio & $\begin{array}{c}95 \% \text { confidence } \\
\text { interval }\end{array}$ & P-value \\
\hline Never-smokers & 5.07 & $3.01-8.53$ & $<0.001$ \\
Normal fibrinogen & 2.63 & $1.53-4.51$ & $<0.001$ \\
\hline
\end{tabular}

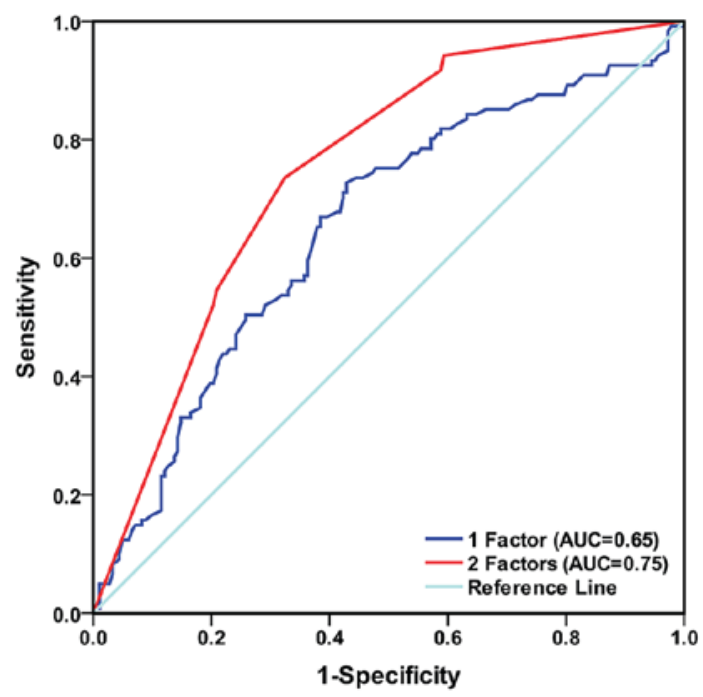

Figure 3. Comparative receiver operator characteristic curves for one factor (fibrinogen) and two factors (fibrinogen and smoking history) for predicting EGFR mutation status. AUC, area under the curve; EGFR, epidermal growth factor receptor.

smoking history were independent predictive factors for EGFR gene mutation status in patients with NSCLC. The genotype of a non-smoking patient who exhibited low plasma fibrinogen concentration $(\leq 3.5)$ always indicated EGFR gene mutations, particularly in females and patients with adenocarcinoma. Conversely, the genotype of a smoking patient who exhibited hyperfibrinogenemia was generally wild-type EGFR, particularly in males and patients with squamous carcinoma. However, the reason for the association between elevated plasma fibrinogen and EGFR gene mutation status of NSCLC remains unknown.

Interleukin-6 (IL-6) is a cytokine which serves an important role in numerous inflammatory diseases, and IL-6R is one subtype of interleukin-6. Previous studies have confirmed that the activation of IL-6R/Janus kinase 1/signal transducer and activator of transcription 3 signaling via autocrine IL-6 production induced resistance to EGFR-TKIs in NSCLC $(24,25)$. Yamaguchi et al (26) revealed a positive correlation between plasma fibrinogen concentration and serum IL-6. Therefore, hyperfibrinogenemia may result in resistance to EGFR-TKIs in patients with EGFR mutations. This requires additional studies with larger sample sizes.

In summary, the present study demonstrates for the first time that plasma fibrinogen is an independent predictive factor for EGFR gene mutation status. Fibrinogen levels are moderately accurate in predicting EGFR gene mutation status when plasma fibrinogen measurements are combined with smoking history in patients with NSCLC. In addition, 
hyperfibrinogenemia is associated with distant organ metastasis and lymphatic metastasis, suggesting that patients with NSCLC with notably elevated fibrinogen level may benefit from aggressive multimodality therapy. However, additional independent studies are required to fully characterize the molecular mechanisms between fibrinogen, EGFR gene mutation status and metastasis.

\section{Acknowledgements}

Not applicable.

\section{Funding}

The present study was funded by the National Natural Science Foundation of China (grant no. 81300029); Science and technology projects in Guangdong Province (grant no. 2012B031800262); Natural Science Foundation of Guangdong Province (grant no. S2013040013505); President Foundation of Nanfang Hospital, Southern Medical University (grant no. 2013Z010); President Foundation of Nanfang Hospital, Southern Medical University (grant no. 2012Z002).

\section{Availability of data and materials}

The datasets used and/or analyzed during the present study are available from the corresponding author on reasonable request.

\section{Authors' contributions}

LYL and LC designed the study. CQ, QL, MC, YaZ, YD, LL and $\mathrm{YuZ}$ collected the data. MY collected and corrected the data. NX performed statistical data processing. and wrote the manuscript. JG participated in the design of the study, interpreted the data, drafted and revised the manuscript, approved the version of the manuscript for publication publication version and is responsible for all aspects of the work and to ensure proper investigation and resolution of issues relating to the accuracy or completeness of any part of the work.

\section{Ethics approval and consent to participate}

Thepresentstudy was approvedby theMedicalEthicsCommittee of NanFang Hospital (approval no. NFEC-2015-009; Guangzhou, China).

\section{Patient consent for publication}

Written informed consent for data to be published is was obtained from all patients.

\section{Competing interests}

The authors declare that they have no competing interests.

\section{References}

1. Chen W, Zheng R, Baade PD, Zhang S, Zeng H, Bray F, Jemal A, $\mathrm{Yu}$ XQ and He J: Cancer statistics in China, 2015. CA Cancer J Clin 66: 115-132, 2016.
2. Paez JG, Jänne PA, Lee JC, Tracy S, Greulich H, Gabriel S, Herman P, Kaye FJ, Lindeman N, Boggon TJ, et al: EGFR mutations in lung cancer: Correlation with clinical response to gefitinib therapy. Science 304: 1497-1500, 2004.

3. Lynch TJ, Bell DW, Sordella R, Gurubhagavatula S, Okimoto RA, Brannigan BW, Harris PL, Haserlat SM, Supko JG, Haluska FG, et al: Activating mutations in the epidermal growth factor receptor underlying responsiveness of non-small-cell lung cancer to gefitinib. N Engl J Med 350: 2129-2139, 2004.

4. Mosesson MW: Fibrinogen and fibrin structure and functions. J Thromb Haemost 3: 1894-1904, 2005.

5. Ma XK, Wen JY, Chen ZH, Lin Q, Li X, Dong M, Wei L, Chen J, Wang TT, Ruan DY, et al: Clinical significance of plasma fibrinogen level in patients with prostate cancer. J Clin Oncol 31, 2013.

6. Son HJ, Park JW, Chang HJ, Kim DY, Kim BC, Kim SY, Park SC, Choi HS and Oh JH: Preoperative plasma hyperfibrinogenemia is predictive of poor prognosis in patients with nonmetastatic colon cancer. Ann Surg Oncol 20: 2908-2913, 2013.

7. Matsuda S, Takeuchi H, Kawakubo H, Fukuda K, Nakamura R, Takahashi T, Wada N, Saikawa Y, Omori T and Kitagawa Y: Cumulative prognostic scores based on plasma fibrinogen and serum albumin levels in esophageal cancer patients treated with transthoracic esophagectomy: Comparison with the Glasgow prognostic score. Ann Surg Oncol 22: 302-310, 2015.

8. Verheul HM, Hammers H, van Erp K, Wei Y, Sanni T, Salumbides B, Qian DZ, Yancopoulos GD and Pili R: Vascular endothelial growth factor trap blocks tumor growth, metastasis formation, and vascular leakage in an orthotopic murine renal cell cancer model. Clin Cancer Res 13: 4201-4208, 2007.

9. Yamashita H, Kitayama J and Nagawa H: Hyperfibrinogenemia is a useful predictor for lymphatic metastasis in human gastric cancer. Jpn J Clin Oncol 35: 595-600, 2005.

10. Shu YJ, Weng H, Bao RF, Wu XS, Ding Q, Cao Y, Wang XA, Zhang F, Xiang SS, Li HF, et al: Clinical and prognostic significance of preoperative plasma hyperfibrinogenemia in gallbladder cancer patients following surgical resection: A retrospective and in vitro study. BMC cancer 14: 566, 2014.

11. Jones JM, McGonigle NC, McAnespie M, Cran GW and Graham AN: Plasma fibrinogen and serum C-reactive protein are associated with non-small cell lung cancer. Lung Cancer 53: 97-101, 2006.

12. Edge S, Byrd DR, Compton CC, Fritz AG, Greene F and Trotti A: AJCC cancer staging manual (7th ed). New York, NY: Springer, 2010.

13. Gatt A, Bonello F, Buttigieg R, Debono S, Brincat P, Grima C, Gatt $P$, Lofaro $T$ and Laspina S: Flow cytometry and thromboelastography to assess platelet counts and coagulation in patients with haematological malignancies. Blood Transfus 12: 479-484, 2014.

14. Kurup A, Lin C, Murry DJ, Dobrolecki L, Estes D, Yiannoutsos CT, Mariano L, Sidor C, Hickey R and Hanna N: Recombinant human angiostatin (rhAngiostatin) in combination with paclitaxel and carboplatin in patients with advanced non-small-cell lung cancer: A phase II study from Indiana University. Ann Oncol 17: 97-103, 2006.

15. Altiay G, Ciftci A, Demir M, Kocak Z, Sut N, Tabakoglu E, Hatipoglu ON and Caglar T: High plasma D-dimer level is associated with decreased survival in patients with lung cancer. Clin Oncol (R Coll Radiol) 19: 494-498, 2007.

16. Kuderer NM, Khorana AA, Lyman GH and Francis CW: A meta-analysis and systematic review of the efficacy and safety of anticoagulants as cancer treatment: Impact on survival and bleeding complications. Cancer 110: 1149-1161, 2007.

17. dos Santos Silva I, De Stavola BL, Pizzi C and Meade TW: Circulating levels of coagulation and inflammation markers and cancer risks: Individual participant analysis of data from three long-term cohorts. Int J Epidemiol 39: 699-709, 2010.

18. Palumbo JS, Talmage KE, Massari JV, La Jeunesse CM, Flick MJ, Kombrinck KW, Jirousková M and Degen JL: Platelets and fibrin(ogen) increase metastatic potential by impeding natural killer cell-mediated elimination of tumor cells. Blood 105: 178-185, 2005.

19. Palumbo JS, Potter JM, Kaplan LS, Talmage K, Jackson DG and Degen JL: Spontaneous hematogenous and lymphatic metastasis, but not primary tumor growth or angiogenesis, is diminished in fibrinogen-deficient mice. Cancer Res 62: 6966-6972, 2002. 
20. Fahham D, Merquiol E, Gilon T, Marx G and Blum G: Insoluble fibrinogen particles for harvesting and expanding attachment-dependent cells and for trapping suspended cancer cells in the presence of blood. Biomed Mater 10: 025010, 2015.

21. Palumbo JS, Kombrinck KW, Drew AF, Grimes TS, Kiser JH, Degen JL and Bugge TH: Fibrinogen is an important determinant of the metastatic potential of circulating tumor cells. Blood 96: 3302-3309, 2000.

22. Wu KL, Tsai MJ, Yang CJ, Chang WA, Hung JY, Yen CJ, Shen CH, Kuo TY, Lee JY, Chou SH, et al: Liver metastasis predicts poorer prognosis in stage IV lung adenocarcinoma patients receiving first-line gefitinib. Lung Cancer 88: 187-194, 2015.

23. Soria JC, Wu YL, Nakagawa K, Kim SW, Yang JJ, Ahn MJ, Wang J, Yang JC, Lu Y, Atagi S, et al: Gefitinib plus chemotherapy versus placebo plus chemotherapy in EGFR-mutation-positive non-small-cell lung cancer after progression on first-line gefitinib (IMPRESS): A phase 3 randomised trial. Lancet Oncol 16 : 990-998, 2015.
24. Nakamichi S, Kubota K, Horinouchi H, Kanda S, Fujiwara Y, Nokihara H, Yamamoto $\mathrm{N}$ and Tamura T: Successful EGFR-TKI rechallenge of leptomeningeal carcinomatosis after gefitinib-induced interstitial lung disease. Jpn J Clin Oncol 43: 422-425, 2013.

25. Ishiguro $\mathrm{Y}$, Ishiguro $\mathrm{H}$ and Miyamoto $\mathrm{H}$ : Epidermal growth factor receptor tyrosine kinase inhibition up-regulates interleukin-6 in cancer cells and induces subsequent development of interstitial pneumonia. Oncotarget 4: 550-559, 2013.

26. Yamaguchi T, Yamamoto Y, Yokota S, Nakagawa M, Ito M and Ogura T: Involvement of interleukin-6 in the elevation of plasma fibrinogen levels in lung cancer patients. Jpn J Clin Oncol 28: 740-744, 1998.

This work is licensed under a Creative Commons Attribution-NonCommercial-NoDerivatives 4.0 International (CC BY-NC-ND 4.0) License. 